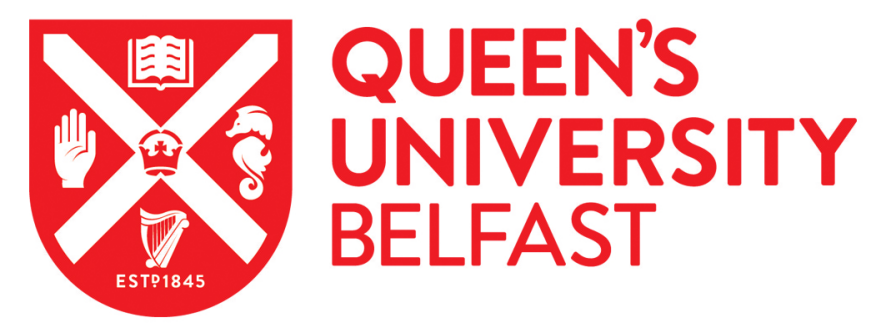

\title{
Joint use of singular value decomposition and Monte-Carlo simulation for estimating uncertainty in surface NMR inversion
}

Legchenko, A., Comte, J-C., Ofterdinger, U., Vouillamoz, J-M., Lawson, F. M. A., \& Walsh, J. (2017). Joint use of singular value decomposition and Monte-Carlo simulation for estimating uncertainty in surface NMR inversion. Journal of Applied Geophysics. https://doi.org/10.1016/j.jappgeo.2017.06.010

Published in:

Journal of Applied Geophysics

Document Version:

Peer reviewed version

Queen's University Belfast - Research Portal:

Link to publication record in Queen's University Belfast Research Portal

\section{Publisher rights}

Copyright 2017 Elsevier

This manuscript is distributed under a Creative Commons Attribution-NonCommercial-NoDerivs License

(https://creativecommons.org/licenses/by-nc-nd/4.0/), which permits distribution and reproduction for non-commercial purposes, provided the author and source are cited.

\section{General rights}

Copyright for the publications made accessible via the Queen's University Belfast Research Portal is retained by the author(s) and / or other copyright owners and it is a condition of accessing these publications that users recognise and abide by the legal requirements associated with these rights.

Take down policy

The Research Portal is Queen's institutional repository that provides access to Queen's research output. Every effort has been made to ensure that content in the Research Portal does not infringe any person's rights, or applicable UK laws. If you discover content in the Research Portal that you believe breaches copyright or violates any law, please contact openaccess@qub.ac.uk. 


\section{Accepted Manuscript}

Joint use of singular value decomposition and Monte-Carlo simulation for estimating uncertainty in surface NMR inversion

Anatoly Legchenko, Jean-Christophe Comte, Ulrich Ofterdinger, JeanMichel Vouillamoz, Fabrice Messan Amen Lawson, John Walsh

PII:

S0926-9851(17)30212-4

DOI: $\quad$ doi: 10.1016/j.jappgeo.2017.06.010

Reference: $\quad$ APPGEO 3295

To appear in: $\quad$ Journal of Applied Geophysics

Received date: 28 February 2017

Revised date: $\quad 8$ June 2017

Accepted date: $\quad 22$ June 2017

Please cite this article as: Legchenko, Anatoly, Comte, Jean-Christophe, Ofterdinger, Ulrich, Vouillamoz, Jean-Michel, Lawson, Fabrice Messan Amen, Walsh, John, Joint use of singular value decomposition and Monte-Carlo simulation for estimating uncertainty in surface NMR inversion, Journal of Applied Geophysics (2017), doi: 10.1016/j.jappgeo.2017.06.010

This is a PDF file of an unedited manuscript that has been accepted for publication. As a service to our customers we are providing this early version of the manuscript. The manuscript will undergo copyediting, typesetting, and review of the resulting proof before it is published in its final form. Please note that during the production process errors may be discovered which could affect the content, and all legal disclaimers that apply to the journal pertain. 


\section{Joint use of singular value decomposition and Monte-Carlo simulation for estimating uncertainty in surface NMR inversion}

by

Anatoly Legchenko ${ }^{1}$, Jean-Christophe Comte ${ }^{2}$, Ulrich Ofterdinger ${ }^{3}$, Jean-Michel Vouillamoz ${ }^{4}$, Fabrice Messan Amen Lawson ${ }^{5}$ and John Walsh ${ }^{6}$

${ }^{1}$ Univ. Grenoble Alps, Institute of Research for Development, IGE, Grenoble, France, E-mail: anatoli.legtchenko@ird.fr

${ }^{2}$ University of Aberdeen, School of Geosciences, UK, E-mail: jc.comte@abdn.ac.uk

${ }^{3}$ Queen's University Belfast, Northern Ireland, E-mail: U.Ofterdinger@qub.ac.uk

${ }^{4}$ Univ. Grenoble Alps, Institute of Research for Development, IGE, Grenoble, France, E-mail: Jean-Michel.Vouillamoz@ird.fr

${ }^{5}$ University of Abomey Calavi, Cotonou, Bénin, E-mail: messan.lawson@ird.fr

6 School of Earth Sciences College of Engineering, Mathematical \& Physical Sciences, Dublin, Ireland, E-mail: ei.dcu@ hslaw.nhoj 


\begin{abstract}
We propose a simple and robust approach for investigating uncertainty in the results of inversion in geophysics. We apply this approach to inversion of Surface Nuclear Magnetic Resonance (SNMR) data, which is also known as Magnetic Resonance Sounding (MRS). Solution of this inverse problem is known to be non-unique. We inverse MRS data using the well-known Tikhonov regularization method, which provides an optimal solution as a trade-off between the stability and accuracy. Then, we perturb this model by random values and compute the fitting error for the perturbed models. The magnitude of these perturbations is limited by the uncertainty estimated with the singular value decomposition (SVD) and taking into account experimental errors. We use $10^{6}$ perturbed models and show that the large majority of these models, which have all the water content within the variations given by the SVD estimate, do not fit data with an acceptable accuracy. Thus, we may limit the solution space by only the equivalent inverse models that fit data with the accuracy close to that of the initial inverse model. For representing inversion results, we use three equivalent solutions instead of the only one: the "best" solution given by the regularization or other inversion technic and the extreme variations of this solution corresponding to the equivalent models with the minimum and the maximum volume of water. For demonstrating our approach, we use synthetic data sets and experimental data acquired in the framework of investigation of a hard rock aquifer in the Northern Ireland (County Donegal).
\end{abstract}

Key words: hydrogeophysics, Ireland, hard rock aquifer, magnetic resonance sounding, MRS, surface NMR, SNMR. 


\section{Introduction}

NMR phenomenon can be observed in nuclei possessing both magnetic moment and angular momentum (hydrogen $\mathrm{H}^{1}$, for example). It consists of selective absorption and transmission of electromagnetic energy by atomic nuclei. Surface NMR method (SNMR), also known as Magnetic Resonance Sounding (MRS) is an application of the NMR phenomenon to groundwater investigation (Semenov, 1987; Schirov et al., 1991; Legchenko and Valla, 2002; Legchenko, 2013; Behroozmand et al., 2015). The resonance behavior of proton magnetic moments ensures that the method is sensitive only to groundwater. Thus, the method is selective. The capacity of a non-invasive detection of groundwater is the competitive advantage of MRS compared to other geophysical tools. For performing MRS measurements, we use a wire loop on the ground. MRS is a large-scale method and the investigated volume depends on the size of the loop. Usually, the same loop acts as a coincident transmitting/receiving antenna. However, separated transmitting and receiving loops can be also used (Legchenko and Pierrat, 2014). The system is tuned to the Larmor frequency (the resonance frequency for hydrogen nuclei of water) known from measurements of the earth's magnetic field. Additionally to detection of groundwater, MRS allows locating water-saturated geological formations. One sounding consists of generating a pulse of oscillating electrical current in the transmitting loop and measuring the amplitude of MRS signal after the pulse is terminated. These measurements are performed with different values of the current in the loop. The shape of the sounding curve allows resolving aquifers using inversion procedure. 
Inversion of MRS data is ill-posed. One of the most popular methods of MRS inversion is the Tikhonov regularization (Tikhonov and Arsenin, 1977). It allows obtaining the Tikhonov solution based on the assumption of the smoothness of the inverse model and selecting the parameter of regularization taking into account experimental errors. The Tikhonov solution is unique, but different equivalent solutions may be also obtained using other inversion procedures. For example, assumptions on the solution shape other than the smoothness constrain can be used for performing blocky inversion (Mohnke and Yaramanci, 2002). Uncertainty in the inverse model can be estimated using different methods. The singular value decomposition (SVD) allows estimating resolution of the MRS inverse problem assuming that the problem is linear (Weichman et al., 2002; Müller-Petke and Yaramanci, 2008). Guillen and Legchenko (2002a) reported application of the linear programming algorithm to investigation of the solution space. Weng (2010) reported application of the Occam's inversion using a nonlinear formulation of the MRS inverse problem. Inversion for the electrical resistivity (Braun and Yaramanci, 2008) as well as inversion using MRS data measured in varying geomagnetic field (Legchenko et al., 2016) also require application of non-linear algorithms. For both, linear and non-linear MRS inverse problems the Monte Carlo inversion has been reported successful (Guillen and Legchenko, 2002b; Chevalier et al., 2014). Parsekian and Grombacher (2015) applied the bootstrap statistics for accelerating uncertainty estimate suitable for linear as well as non-linear inverse problems. One can see that many different approaches can be used but regardless of the inversion scheme, knowledge of the uncertainty in the selected solution is a matter of practical importance. 
We developed a simple and robust approach for investigating uncertainty in each particular inverse model by applying random perturbations to this model. We present the case of application of this approach to the inverse models obtained with the Tikhonov regularization method, but random perturbations can be also applied when using any other inversion algorithm. We carried out field tests aiming to evaluate MRS efficiency and to optimize the methodology of MRS application to investigation of hard-rock aquifers. Any hard-rock aquifer is an important, but difficult target for geophysics and hydrogeology because of their high heterogeneity and generally low water content. In this paper, we use MRS data measured in Ireland, but our results can be easy extended to other parts of the world.

In Ireland, highly heterogeneous weathered/fractured hard rock aquifers underlay over $60 \%$ of the island (Comte et al., 2012). These aquifers have generally low permeability and porosity and are typical for post-glaciated temperate regions covering large areas in the Northern hemisphere (Comte et al., 2012; Cassidy et al., 2014). The recent glaciations have eroded the shallow part of the bedrock and overlaid this formation by highly heterogeneous glacial and fluvioglacial materials of variable thicknesses. Geological heterogeneity controls the groundwater recharge and aquifer properties (Misstear et al, 2008; Comte et al., 2012; Cai and Ofterdinger, 2015). Under these conditions, sparse borehole information may be often incomplete and the MRS method has the potential to provide a valuable contribution to investigation of groundwater resources.

\section{Background}


For performing MRS measurements, we use the coincident loop configuration. The loop is energized by pulses of alternating current $i(t)=I_{0} \cos \left(\omega_{0} t\right)$ and acts as the transmitter. The pulse moment $q=I_{0} \tau$ is a product of the current amplitude $I_{0}$ and pulse duration $\tau$. After the pulse is cut off, the loop is switched to the receiver. In nonmagnetic rocks, one pulse is sufficient for measuring the free induction decay signal $e_{0}$ as a function of the pulse moment $q$. Assuming the horizontal stratification, the amplitude of MRS signal can be computed as

$$
e_{0}(q)=\frac{\omega_{0}}{I_{0}} \int_{V} B_{\perp} M_{\perp} w(z) d V,
$$

where $B_{\perp}$ is the transversal component of the loop magnetic field, $M_{\perp}$ is the transversal component of the nuclear magnetization and $w(z)$ is the water content distribution versus depth (Legchenko and Valla, 2002). Under near resonance conditions

$$
M_{\perp}=M_{0} \sin \left(\gamma B_{\perp} \tau / 2\right) .
$$

The water content in the subsurface $w(z)$ is solution of the integral Equation (1). For resolving this equation, we approximate it by a system of algebraic equations

$$
\mathbf{A w}=\mathbf{e}_{0},
$$


where $\mathbf{A}=\left[a_{i, j}\right]$ is a rectangular matrix of $I \times J, \mathbf{e}_{0}=\left(e_{01}, e_{02}, . ., e_{0 i}, \ldots, e_{0 I}\right)^{T}$ is the set of experimental data and $\mathbf{w}=\left(w_{1}, w_{2}, . ., w_{j}, . ., w_{j}\right)^{T}$ is the water content.

Discretization of the Equation (1) consists of defining the number and values of the pulse moment and the depth $z_{j}$ and the thickness $\Delta z_{j}$ of layers in the inverse model that compose columns in the matrix $\mathbf{A}$ with respect to

$$
\Delta z_{j}=z_{j+1}-z_{j}, \quad z_{\text {max }}=\sum_{j=1}^{J} \Delta z_{j},
$$

where $\Delta z_{1} \leq \Delta z_{2} \leq . . \leq \Delta z_{j} \leq . . \leq \Delta z_{J}$ and $z_{\max }$ is the maximum depth of water saturated formation that may contribute to measured MRS signal. In general, the number of pulses should be minimized for accelerating fieldwork but should not be less than the number of layers in the Equation (4) for not degrading resolution (Legchenko and Shushakov, 1998; Dalgaard et al., 2016). We recommend to select pulses so that each pulse moment $q_{i}$ corresponds to the maximum of the MRS signal from one model layer $\Delta z_{j}$. In practice, this rule is usually not respected because pulses are set by the hardware following approximately the logarithmic distribution of the pulse moments. For selecting the thickness of each layer $\left(\Delta z_{j}\right)$, we compute the correlation matrix $\mathbf{R}$ composed of the Pearson correlation coefficients between columns of the matrix $\mathbf{A}$

$$
\mathbf{R}=\mathbf{D A}^{\mathbf{T}} \mathbf{A D}
$$

where $\mathbf{D}$ is a diagonal matrix with the elements 


$$
d_{j, j}=\frac{1}{\sqrt{\sum_{i=1}^{I} a_{i, j}^{2}}} .
$$

The discretization rule consists of selecting $\Delta z$ and the correlation coefficient $(r)$ between the neighboring layers so that $r=r_{j, j+1}=r_{j+1, j+2}=\ldots=r_{J-1, J}$. Thus, varying $r$ we may obtain different distributions with respect to Equation (4). Straightforward application of this rule may provide very thin shallow layers. In practice, extensive horizontal thin layers is a rare case and we limit the minimal thickness by setting $\Delta z_{j} \geq 0.5 \mathrm{~m}$.

The singular value decomposition (SVD) allows investigating resolution of the MRS inverse problem. For that, we present the matrix $\mathbf{A}$ as a product of three orthogonal matrixes: $\mathbf{U}, \mathbf{V}$, and $\mathbf{S}$ (Aster et al., 2005)

$$
\mathbf{A}=\mathbf{U S V}^{\mathbf{T}} \text {, }
$$

where $\mathbf{U}$ is an $I \times I$ matrix representing the data space, $\mathbf{V}$ is an $J \times J$ matrix representing the model space and $\mathbf{S}$ is an $I \times J$ diagonal matrix with nonnegative diagonal elements (singular values). The model resolution matrix $\mathbf{R}_{m}$ describing how well the recovered model is able to represent the original model is

$$
\mathbf{R}_{m}=\mathbf{V F V}^{\mathbf{T}},
$$


where $\mathbf{F}$ is an $J \times J$ diagonal matrix representing the effect of regularization (the filter factor). Without regularization $\mathbf{F}=\mathbf{I}$ with $\mathbf{I}$ being the identity matrix. The model will be perfectly recovered by the inversion if $\mathbf{R}_{m}=\mathbf{I}$.

The discretization is an iterative procedure. It consists of: 1) selecting the number and distribution of pulse moments (often $I$ is provided by the hardware during fieldwork and cannot be increased); 2) selecting the number of model layers $J$ in Equation (3) with respect to $J \leq I ; 3$ ) computing the thicknesses of the model layers $\left(\Delta z_{j}\right)$ and the model resolution matrix $\left.\mathbf{R}_{m} ; 4\right)$ discretization is completed when $\mathbf{R}_{m} \approx \mathbf{I}$

Sensitivity of the inversion to experimental and computational errors can be characterized by the condition number, which is the ratio of the maximum $\left(s_{\max }\right)$ and minimum $\left(s_{\text {min }}\right)$ singular values. For stable inversion the matrix $\mathbf{A}$ should have

$$
\operatorname{cond}(\mathbf{A})=s_{\text {max }} / s_{\text {min }} \rightarrow 1
$$

For estimating uncertainty caused by experimental noise we assume independent and identically distributed normal data errors $\sigma^{2}$. In this case, the covariance for the model becomes

$$
\operatorname{Cov}(\mathbf{w})=\sigma^{2} \mathbf{V F S} \mathbf{S}^{-2} \mathbf{V}^{\mathbf{T}}
$$

The corresponding $95 \%$ confidence intervals for $\mathbf{w}$ can be computed as 


$$
\mathbf{w}_{0.95}=1.96 \times \sqrt{\operatorname{diag}(\operatorname{Cov}(\mathbf{w}))},
$$

and its standard deviation as

$$
\Delta \mathbf{w}=\mathbf{w}_{0.95} / 1.96 \approx \mathbf{w}_{0.95} / 2
$$

For inversion of MRS data, the Tikhonov regularization method (Tikhonov and Arsenin, 1977) is often used. Minimization of a Tikhonov functional $M(\eta)$ provides an approximate solution of the Equation (3)

$$
M(\eta)=\left\|\mathbf{A} \mathbf{w}-\mathbf{e}_{\mathbf{0}}\right\|_{L_{2}}+\eta\|\mathbf{w}\|_{L_{2}}=\min
$$

where $\eta>0$ is called the regularization parameter. Regularization acts as a filter for the solution. The Tikhonov filter function $\mathbf{F}$ is a diagonal matrix with the diagonal elements given by the filter factors is

$$
f_{j}=\frac{s_{j}^{2}}{s_{j}^{2}+\eta},
$$

where $s_{j}$ are the singular values.

MRS provides the water content and the thickness of water-saturated formation, which allows estimating the volume of water per surface unit

$$
V=\sum_{j=1}^{J} w_{j} \Delta z_{j}
$$

The water volume is a more stable parameter than the water content $w_{j}$ and the thickness $\Delta z_{j}$ separately (Legchenko et al., 2004). However, one should be careful 
when using the water volume estimates provided by MRS because the water volume can be reliable only for formations that MRS inversion is able to resolve. For example, the resolution of the MRS inversion is known to degrade with increased depth. Consequently, MRS estimation of the water volume in deep layers may be erroneous without additional information about the depth and the thickness of these layers.

\section{Inversion procedure}

For performing inversion, we have to approximate an integral Equation (1) by a matrix Equation (3). The first step consists of defining of the maximum depth of investigation $z_{\max }$. It can be estimated taking into account measuring conditions (loop, pulse moment, rocks electrical conductivity) and assuming as a test layer a 1-m-thick layer of bulk water (Legchenko et al., 2002). Hunter and Kepic (2005) alternatively suggested to use a homogeneous test layer of infinite thickness with the water content corresponding to that expected in the investigated formation. The depth to the top of this layer producing measurable MRS signal is considered as $z_{\text {max }}$. In practice, a small difference in $z_{\text {max }}$ estimation obtained with these two approaches is not critical because it only affects the water content in the last layer that cannot be resolved by inversion anyway. Then, we prescribe the thickness of each model layer to increase progressively with depth and with respect to conditions given by Equation (4). We define the number of the model layers for inversion so that when setting $\eta=0$ we obtain $\mathbf{R}_{m} \approx \mathbf{I}$, where I is the identity matrix. With such a discretization, inversion is able to resolve Equation 
(3) for noiseless data. In practice, these ideal conditions do not exist and consequently, the solution can be obtained with some uncertainty

$$
\mathbf{w}=\mathbf{w} \pm \Delta \mathbf{w}
$$

where $\Delta \mathbf{w}$ is an estimate of the uncertainty (Equation 12). Note that the SVD assumes that the inversion is linear and that the noise is normally distributed. However, these assumptions are not always justified for MRS data. Indeed, for inversion we assume a non-negative solution and optimization is carried out considering complex MRS signal but optimizing only amplitudes (Chevalier et al., 2014). Thus, for real data, the SVD estimate of the uncertainty is an approximation. For a non-linear problem, the inversion and uncertainty analysis can be performed using Monte Carlo based algorithms (Sambridge and Mosegaard, 2002). However, an approach based on the use of an entirely randomized generation of models is known very inefficient and hence time-consuming. For accelerating convergence, different assumptions on the solution are usually applied. We propose to use the Monte Carlo approach for investigating uncertainty in the inverse model provided by any inversion method (regularization, block inversion etc). The inverse problem can be linear as well as non-linear.

In this paper, we obtain $\mathbf{w}_{\text {mod }}$ using the Tikhonov regularization method assuming the non-negative water content. Then, we perturb this model within the uncertainty given by the SVD. The water content in each layer of the perturbed model thus becomes

$$
\left\{\begin{array}{c}
w_{j}=w_{\bmod j}+w_{0.95 j} \times x_{n, j} \\
\text { if } \quad w_{j}<0 \quad \text { then } \quad w_{j}=0
\end{array} .\right.
$$


For generating pseudo-random numbers $x_{n, j}(n=1,2, . ., N)$ uniformly distributed between -1 and 1, we use the multiply-with-carry method (Marsaglia and Zaman, 1991). Note that each perturbed model respects conditions given by Equation (16), but not necessary fits well experimental data. An estimate of the fitting error is given by the root mean square error

$$
R M S E=\sqrt{\frac{1}{I} \sum_{i=1}^{I}\left(e_{i}-e_{\bmod i}\right)^{2},}
$$

where $e_{i}$ and $e_{\bmod i}$ are measured and theoretical amplitudes respectively.

Let us generate $N$ perturbed models and for each model we compute the fitting error $R M S E_{n}$. We consider these values as a set of random numbers characterized by the mean $M$ and the standard deviation $S$

$$
\left\{\begin{array}{c}
M=\frac{1}{N} \sum_{n=1}^{N} \operatorname{RMSE}_{n} \\
S=\sqrt{\frac{1}{N} \sum_{n=1}^{N}\left(R M S E_{n}-M\right)^{2}}
\end{array} .\right.
$$

The obtained set of random values can be also characterized by the probability density function $(P D F)$. The $P D F$ is a function, whose value at any given point provides a relative likelihood that the value of the random variable ( $R M S E$ in our case) would equal that point. If we assume a normal distribution of RMSE then the PDF can be computed using corresponding mean and standard deviation (Billingsley, 1979). The PDF can be also computed statistically. For that, we count the number of perturbed models with $R M S E$ corresponding to each of the equal intervals of the 
$\operatorname{RMSE}\left(\Delta_{R M S E}\right)$ so that $\sum\left(\Delta_{R M S E}\right)=R M S E_{\max }-R M S E_{\min }$. For verifying whether the distribution of RMSE is normal or not, we compute the PDF using both the mean and the standard deviation and statistically. If the normal distribution curve fits the statistical one then the distribution is normal. Otherwise, it is not. The water volume $V$ can be treated in the similar way to $R M S E$.

The SVD provides a linear projection of noise from the data space to the model space. The model space may contain a great number of solutions perturbed by noise and the SVD does not suggest how to select the best solution. For estimating uncertainty in the inverse model $\mathbf{w}_{\text {mod }}$ provided, in our case, by regularization, we select only solutions that are equivalent to $\mathbf{w}_{\text {mod }}$. For selecting the extreme inverse models from many equivalent models, we propose to use such a physically justified parameter such as the volume of water under MRS loop. Thus, if we use $N$ equivalent models then the extreme solutions become

$$
\left\{\begin{array}{l}
V_{\text {min }}=\min _{N}\left(V_{n}\right) \\
V_{\max }=\max _{N}\left(V_{n}\right) \\
R M S E\left(V_{\text {min }}\right) \approx \operatorname{RMSE}\left(V_{\text {mod }}\right) \approx \operatorname{RMSE}\left(V_{\max }\right)
\end{array} .\right.
$$

These three equivalent inverse models $\left(V_{\min } \leq V_{\bmod } \leq V_{\max }\right)$ provide the vertical distribution of the water content corresponding to the extreme variations of the water volume thus showing the uncertainty in the inversion results.

\section{Numerical results}


For demonstration, we use synthetic data assuming a $25 \times 25 \mathrm{~m}^{2}$ figure-eight loop (Trushkin et al., 1994) with two turns of wire. The loop is energized by pulses of electrical current with the maximum pulse moment of $5000 \mathrm{~A}-\mathrm{ms}$, the inclination of the earth's magnetic field of $55^{\circ}$, the Larmor frequency of $2111 \mathrm{~Hz}$ and the resistivity of the subsurface of $100 \mathrm{ohm}-\mathrm{m}$.

First, we estimate the maximum depth of investigation by computing the amplitude of the MRS signal versus depth (Figure 1a). A 1-m-thick layer of bulk water located at the depth of $55 \mathrm{~m}$ produces the signal of $5 \mathrm{nV}$, which approximately corresponds to the practical threshold of the MRS instrument limited by ambient electromagnetic noise (Legchenko and Pierrat, 2014). For this example, we define $z_{\max }=55 \mathrm{~m}$. The depth interval of 0-55 $\mathrm{m}$ is divided into 15 layers with respect to Equation (4). The thickness of these layers and the diagonal elements of the model resolution matrix $\mathbf{R}_{m}$ are presented in Figures (1b) and (1c) respectively. Rather high value of the condition number ( $\operatorname{cond}(\mathbf{A})=1390$ ) suggests that inversion will be sensitive to experimental and other errors.

For the first example, we generate synthetic data set assuming a model consisting of a 10-m-thick water-saturated layer ( $w=5 \%, T_{2}^{*}=200 \mathrm{~ms}$ ) located at a well-resolved depth of $5 \mathrm{~m}$. Synthetic signals have been contaminated by normally distributed random noise representing about $7 \%$ of the signal maximum amplitude. Results of inversion of this data set are presented in Figure (2). 
Figure (2a) shows the water content in the initial model and the inverse model given by regularization versus depth. The standard deviation of the water content was estimated with the SVD. It shows that deep layers have much higher relative uncertainty in comparison with shallow ones. Figure (2b) presents the $\mathrm{V}_{\max }$ and $\mathrm{V}_{\min }$ solutions. The diagonal elements of the model resolution matrix (Figure 2c) predict the most reliable results between approximately 5 and $25 \mathrm{~m}$. A poor resolution close to the surface can be explained by insufficient number of pulses corresponding to small values of the pulse moment (insufficient sampling). One can see that the initial model located between 5 and $15 \mathrm{~m}$ is reasonably well resolved. However, due to insufficient resolution and the noise influence, artifacts have been generated below $30 \mathrm{~m}$. Figure (3) demonstrates that the theoretical signals computed considering these equivalent solutions fit synthetic data equally well $(R M S E=2.9 \mathrm{nV})$.

Figure (2) shows results obtained using data with a high signal to noise ratio. However, the solution is composed of the component $\mathbf{w}$ representing MRS signal and the component $\Delta \mathbf{w}$ representing noise (Equation 16). Equations (10) - (12) show that when noise $(\sigma)$ is increasing $\Delta \mathbf{w}$ is also increasing. If $\sigma$ becomes larger, then the solution will represent rather noise than the signal. If $\sigma \rightarrow 0$, then $\Delta \mathbf{w} \rightarrow 0$ and one may expect that the solution becomes exact and unique. Unfortunately, it is not true because imperfection of the mathematical model, accumulation of computational errors and geological noise render inversion results non-unique anyway and the $V_{\max }$ and $V_{\min }$ equivalent solutions may exist even for noiseless data.

Figures (4a) and (4b) show the PDF of $R M S E$ and the PDF of $V$ respectively. One can see that for this example, the PDF of RMSE does not correspond well to the 
normal distribution whereas the $P D F$ of $V$ does. Figure (4c) presents the relationship between $V$ and RMSE. The mean $V$ (solid black line) and the standard deviation of $V$ (dashed lines) versus $R M S E$ show uncertainty in the volume estimate for the equivalent models corresponding to each value of $R M S E$. Crosses show volumes corresponding to the $\mathrm{V}_{\max }, \mathrm{V}_{\text {regulariz }}$ and $\mathrm{V}_{\min }$ equivalent solutions.

We generated $N$ perturbed models (in this paper we use $N=10^{6}$ ) with respect to the 95\% confidence interval computed using the SVD (Equation 17). However, Figure (4a) shows that only a relatively small number of these models fit MRS amplitudes with the prescribed $R M S E=2.9 \mathrm{nV}$. The great majority of these models fit the amplitudes with higher error. Table (1) presents a summary of the water volume estimates for all the examples discussed in this paper.

Because of insufficient resolution for deep layers, inversion of a 1-layer model overestimates the water volume due to inexistent deep layers generated by inversion. An artifact can be recognized by analyzing the SVD-estimated resolution and by making comparison of $\mathrm{V}_{\min }$ and $\mathrm{V}_{\max }$ solutions. Usually, a large difference in the water content observed between these two solutions may point to an artifact. For example, Figure (2b) shows that the deep layer vary significantly which suggests an artifact.

For comparison, we show inversion of a model composed of two layers of equal thickness and water content $\left(w=5 \%, T_{2}^{*}=200 \mathrm{~ms}\right)$ located at a depth of 5 and $30 \mathrm{~m}$ (Figure 5).

One can see that if a deep layer exists then all the equivalent models show it. In practice, to recognize an artifact is not always easy and we recommend constraining 
inversion with additional knowledge about the subsurface. For example, when investigating hard rock aquifers, Electrical Resistivity Tomography (ERT) can delineate the weathered part of the subsurface with a high degree of reliability (Hertrich and Yaramanci, 2002; Legchenko et al., 2006; Descloitres et al., 2008; Günther and MüllerPetke, 2012). Joint use of Transient EM method and MRS for hydrogeological purposes has been reported when investigating sand and clay formations (Goldman et al., 1994; Behroozmand et al., 2012; Vouillamoz et al., 2012; Kemgang et al., 2015).

\section{Experimental results}

We performed MRS measurements in the Republic of Ireland (the Gortinlieve Catchment in County Donegal) in 2010 and 2016 (Figure 6). The MRS stations were located as close as possible to an ERT profile and boreholes accomplished during previously performed study (Comte at al., 2012).

In 2010, we used the NUMIS ${ }^{\text {PLUS }}$ MRS Instrument and in 2016 the NUMIS ${ }^{\text {POLY }}$ MRS system, both manufactured by IRIS Instruments. We used the figure-eight square loops of three sizes: 1) 25-m-side with two turns, 2) 37.5-m-side with one turn, 3) 50-mside with one turn. In 2016, one reference loop (multi-turn loop of 5-m-side) was used during data acquisition aiming to improve the signal to noise ratio. In the Gortinlieve Catchment, MRS soundings were located near boreholes included in the National groundwater-monitoring network of the Environmental Protection Agency of Ireland. We present two of them as examples of the inversion.

Borehole GO-3 is located in the valley floor and the bedrock is covered by about 10 m of glacio-fluvial sandy clay, with occurrence of peat and gravel beds (Figure 7a). The water table is shallow (about $2 \mathrm{~m}$ deep). The shallow part of the bedrock is weathered 
and highly fractured. It represents a water transitional formation down to approximately $30 \mathrm{~m}$. Below $30 \mathrm{~m}$, water flows preferentially through a limited number of interconnected fractures (Caulfield et al., 2014; Cai et al., 2015). The resistivity log extracted from the ERT profile (Figure 7b) shows a 10-m-thick low-resistivity formation (200 ohm-m) corresponding to the glacio-fluvial overburden. Between 10 and $20 \mathrm{~m}$ deep, the resistivity of about $700 \mathrm{ohm}-\mathrm{m}$ has been interpreted as clay-leached topmost horizon of the weathered schists (Comte at al., 2012; Cassidy et al., 2014). The underlying layer of about $400 \mathrm{ohm}-\mathrm{m}$ down to a depth of about $40 \mathrm{~m}$ corresponds to a clay-rich weathered schist formation. The gradual increase in resistivity with depth below $40 \mathrm{~m}$ was explained by the decrease in weathering intensity, clay content and fractures density. At this site, we performed MRS measurements using a 50-m-side figure-eight loop. The maximum depth of water detection estimate suggest $z_{\max } \approx 70 \mathrm{~m}$. Inversion (Figures $7 \mathrm{c}$ and $7 \mathrm{~d}$ ) shows a relatively high water content in the upper (coarser) part of glaciofluvial overburden (5 to 6\%) and less water (2 to $3 \%$ ) below (clay-leached schists). All the equivalent solutions detect water below $30 \mathrm{~m}$ thus suggesting that the bedrock should contain water. However, estimated resolution (Figure 7e) shows that layers below $30 \mathrm{~m}$ cannot be accurately resolved and thus, quantification of deep water cannot be done using MRS alone.

Figures (8a) and (8b) show that the large majority of the perturbed solutions fit experimental data with much higher $R M S E$ than the solution given by regularization $(R M S E=5.1 n V) . \mathrm{V}_{\text {regulariz }}$ solution provides the water volume estimate with the uncertainty given by $\mathrm{V}_{\min }$ and $\mathrm{V}_{\max }$ solutions (Figure 8c and Table 1). Note that because 
of the poorly resolved deep water-saturated formation $(>30 \mathrm{~m})$ the water volume estimate may be also inaccurate.

MRS measurements near borehole GO-1 (Figure 9) have been performed using a 37.5-m-side figure-eight loop and the maximum depth of water detection has been estimated at $60 \mathrm{~m}$. This station is located about $1 \mathrm{~km}$ uphill from the borehole GO-3 and is about $140 \mathrm{~m}$ higher in altitude. The soil layer is practically absent, which allows direct estimation of the water content in bedrock. Previous hydrogeological studies suggest insignificant seasonal water circulation in the first $5 \mathrm{~m}$ of the subsurface. The resistivity $\log$ shows values of more about $2500 \mathrm{ohm}-\mathrm{m}$ thus confirming very small amount of water in the subsurface. Between about 5 and $15 \mathrm{~m}$, resistivity drops to about $1500 \mathrm{ohm}-\mathrm{m}$. This value corresponds to a weathered/fractured psammitic schist and values higher than $2000 \mathrm{ohm}-\mathrm{m}$ below $20 \mathrm{~m}$ to a slightly decomposed psammitic shists (Comte et al., 2012). MRS suggests some water between 15 and 35 m approximately. The water content in this layer was estimated about $1 \%$, which is a reasonable value for a saturated psammitic schist. Figure $(9 \mathrm{~d})$ shows that the $\mathrm{V}_{\min }$ solution does not show water below $35 \mathrm{~m}$ and consequently we consider the second water-saturated layer shown by the $\mathrm{V}_{\max }$ solution below $45 \mathrm{~m}$ as unreliable.

Figure (10) shows measured amplitude of the MRS signal at these two stations and the theoretical fits obtained with these three equivalent solutions.

\section{Discussion}

Inversion of MRS data is a typical problem in geophysics. The non-uniqueness of the solution shifts the main difficulty from being a problem of fitting experimental data with an inverse model to being a problem of selecting the best model out of many 
equivalent models, sometimes rather different. Such a selection can be done by imposing additional criteria based on knowledge and/or assumptions on the solution shape. For example, the regularization method assumes that the solution has to be smooth. For such a selection, we propose to use a physically justified criterion: the volume of water, which can be calculated for each inverse model. Taking into account that selection of the "best" model is more or less subjective; we propose to use three inverse models instead of the only one. Thus, the solution is composed of the model obtained with the regularization or any other inversion technic (the best model) and two equivalent models corresponding to the maximum and the minimum volumes. Knowledge of the water volume in the subsurface is itself an important issue for hydrogeologists. In addition, we obtain an estimate of the uncertainty for the water volume and corresponding water content distributions. However, one should be careful with using the water volume because it can be reliable only within the depth interval where MRS has an acceptable resolution. For investigating deep targets where resolution is poor, inversion has to be constrained using additional knowledge of the subsurface (boreholes, other measurements etc).

When the problem considered linear, the SVD analysis provides a statistically justified estimate of the uncertainty. For the non-linear inverse problem, the MonteCarlo simulation is often recommended. We investigate uncertainty by combining both approaches.

First, we carry out inversion and select a model, which we consider the best. Obviously, this inverse model must fit experimental data with acceptable accuracy. Then, we apply random perturbations to this model. We limit the magnitude of these 
perturbations by the SVD estimated uncertainty given by the $95 \%$ confidence interval. Thus, we apply local and statistically justified perturbations to the inverse model that greatly accelerates Monte-Carlo modeling. All the perturbed models create the solution space around the "best" model. This solution space is characterized by the mean, the standard deviation and the probability density function $(P D F)$. The $P D F$ allows insight into the entire solution space for additional analysis. Our results, both numerical and experimental, show that only a small part of the perturbed models fit experimental data with acceptable accuracy. This observation suggests that the SVD provides very general estimates that may be difficult to use in practice. Understanding of the RMSE distribution allows reducing the solution space given by the SVD by only equivalent models that fit experimental data with desirable accuracy. We used this approach for interpretation of real data from our survey in the Northern Ireland. We observed a good consistency of MRS results with other available data (boreholes, ERT, hydrological modeling).

For processing these data we used a standard HP lap-top computer with the 64 bit processor (Intel® Core ${ }^{\mathrm{TM}} \mathrm{i}-75600 \mathrm{U}$ CPU @ $2.60 \mathrm{GHz}$ ) and the $16 \mathrm{~Gb}$ RAM. The linear inversion with SVD takes about $3 \mathrm{~s}$. The Monte-Carlo simulation (14 layers, $16 \mathrm{q}$ values, $10^{6}$ combinations) takes about $14 \mathrm{~s}$.

\section{Conclusions}

In this paper, we propose a simple and robust approach for estimating uncertainty in the inversion of MRS data. For that, we apply random perturbations to the inverse model given by the Tikhonov regularization. The perturbations are limited by the uncertainty estimated applying the SVD analysis. The use of an inverse model that 
already fits experimental data greatly accelerates the Monte Carlo simulations and allows overcoming the problem related to heavy computing, which is often considered as an important limitation of the Monte Carlo method. In our study, we use the Tikhonov regularization, but this approach of investigating uncertainty can be also applied to the analysis of inverse models obtained with other than regularization inversion schemes.

We applied MRS to investigation of a weathered/fractured hard-rock aquifer in the Gortinlieve Catchment in the Republic of Ireland and presented two examples. One MRS station was located in the valley floor and another one located near the hilltop about $140 \mathrm{~m}$ higher in altitude. The water content in this psammitic schist aquifer was estimated with MRS at about $1 \%$ in deep bedrock. In the upper most weathered/fractured bedrock, MRS shows 2 to $3 \%$, against 5 to $6 \%$ in the overlying glaciofluvial deposits. These results are consistent with other data (boreholes geological logs, ERT data, hydrological monitoring data) and previous hydrogeological conceptual understanding.

\section{Acknowledgements}

This work was supported by a grant from Labex OSUG@2020 (Investissements d'avenir - ANR10 LABX56). We also thank the French National Program (ANR) "Investment for Future - Excellency Equipment" project EQUIPEX CRITEX (grant \# ANR-11-EQPX-0011) for providing MRS equipment. The Geological Survey of Ireland (GSI) provided financial support for the fieldwork in the framework of the Geoscience Research Program (2016). 


\section{References}

Aster, R.C., Borchers, B., Thurber, C.H., 2005. Parameter Estimation and Inverse Problems, Elsevier Academic Press.

Behroozmand, A., Auken, E., Fiandaca, G., and Christiansen, A.V., 2012. Improvement in MRS parameter estimation by joint and laterally constrained inversion of MRS and TEM data, Geophysics, 77, WB191-WB200, doi: 10.1190/GEO2011-0404.1.

Behroozmand, A.A., Keating, K., and Auken, E., 2015. A Review of the Principles and Applications of the NMR Technique for Near-Surface Characterization, Surveys in geophysics, 36(1), 27-85, doi: 10.1007/s10712-0149304-0.

Billingsley, P., 1979. Probability and Measure, John Wiley and Sons, New York, Toronto, London, ISBN 0-471-00710-2.

Braun, M., and Yaramanci, U., 2008. Inversion of resistivity in Magnetic Resonance Sounding, Journal of Applied Geophysics 66, 151-164, doi: 10.1016/j.jappgeo.2007.12.004.

Cai, Z., and Ofterdinger, U., 2016. Analysis of groundwater-level response to rainfall and recharge estimates in fractured hard rock aquifers, NW Ireland, Journal of Hydrology, 535, 71-84., doi: 10.1016/j.jhydrol.2016.01.066.

Cassidy, R., Comte, J-C., Nitsche, J., Wilson, C., Flynn, R., Ofterdinger, U., 2014. Combining multi-scale geophysical techniques for robust hydro-structural characterisation in catchments underlain by hard rock in post-glacial regions, Journal of Hydrology, 517, 715-731, doi: 10.1016/J.JHYDROL.2014.06.004. 
Caulfield, J., Chelliah, M., Comte, J-C., Cassidy, R., Flynn, R., 2014. Integrating petrography, mineralogy and hydrochemistry to constrain the influence and distribution of groundwater contributions to baseflow in poorly productive aquifers: Insights from Gortinlieve catchment, Co. Donegal, NW Ireland, Science of The Total Environment, 500-501, 224-234, doi: 10.1016/j.scitotenv.2014.08.105.

Chevalier, A., Legchenko, A., Girard, J-F., Descloitres, M., 2014. 3D Monte Carlo inversion of Magnetic Resonance measurements, Geophysical Journal International, 198, 216-228, doi: 10.1093/gji/ggu091.

Comte, J-C., Cassidy, R., Nitsche, J., Ofterdinger, U., Pilatova, K, and Flynn, R., 2012. The typology of Irish hard-rock aquifers based on an integrated hydrogeological and geophysical approach, Hydrogeology Journal, 20, 1569-1588, doi: 10.1007/s10040-012-0884-9.

Dalgaard, E.M., Müller-Petke, M., and Auken, E., 2016. Enhancing SNMR model resolution by selecting an optimum combination of pulse moments, stacking, and gating, Near Surface Geophysics, 14(3), 243-253, doi: 10.3997/1873-0604.2016004.

Descloitres, M., Ruiz, L., Sekhar, M., Legchenko, A., Braun, J-J., M. S. Mohan Kumar, Subramanian, S., 2008. Characterization of seasonal local recharge using Electrical Resistivity Tomography and Magnetic Resonance Sounding, Hydrological Processes, 22(3), 384-394, doi: 10.1002/hyp.6608.

Goldman, M., Rabinovich, B., Rabinovich, M., Gilad, D., Gev, I., and Schirov, M., 1994. Application of integrated NMR-TDEM method in ground water exploration in Israel, Journal of Applied Geophysics, 31, 27-52, doi: 10.1016/09269851(94)90045-0. 
Guillen, A., and Legchenko, A., 2002a. Application of linear programming techniques to the inversion of proton magnetic resonance measurements for water prospecting from the surface, Journal of Applied Geophysics, 50, 149-162, doi: 10.1016/S0926-9851(02)00136-2.

Guillen, A., and Legchenko, A., 2002b. Inversion of surface nuclear magnetic resonance data by an adapted Monte Carlo method applied to water resource characterization, Journal of Applied Geophysics, 50, 193-205, doi: 10.1016/S09269851(02)00139-8.

Günther, T., and Müller-Petke, M., 2012. Hydraulic properties at the North Sea island Borkum derived from joint inversion of magnetic resonance and electrical resistivity soundings, Hydrology and Earth System Sciences, 16, 3279-3291, doi: 10.5194/hess-16-3279-2012.

Hertrich, M., and Yaramanci, U., 2002. Joint inversion of Surface Nuclear Magnetic Resonance and Vertical Electrical Sounding, Journal of Applied Geophysics, 50, 179-191, doi:10.1016/S0926-9851(02)00138-6.

Hunter, D., and Kepic, A., 2005. Surface nuclear magnetic resonance signal contribution in conductive terrains, Exploration Geophysics, 36(1), 73-77, doi: 10.1071/EG05073.

Kemgang, D.T., Boucher, M., Ngounou Ngatcha, B., Favreau, G., Mvondo, V.Y.E., Ibrahim, M., Legchenko, A. and Goni, I.B., 2015. Magnetic Resonance Soundings for characterizing the Quaternary aquifer in the Lake Chad Basin, A case history from Cameroon and Niger, Nigerian Association of Hydrogeologist, Water Resources, 25, 69-91. 
Legchenko, A.V., and Shushakov, O.A., 1998. Inversion of surface NMR data, Geophysics, 63, 75-84, doi: 10.1190/1.1444329.

Legchenko, A., and Valla, P., 2002. A review of the basic principles for proton magnetic resonance sounding measurements, Journal of Applied Geophysics, 50, 319, doi: 10.1016/S0926-9851(02)00127-1.

Legchenko, A., Baltassat, J-M., Beauce, A., and Bernard, J., 2002. Nuclear magnetic resonance as a geophysical tool for hydrogeologists, Journal of Applied Geophysics, 50, 21-46. doi: 10.1016/S0926-9851(02)00128-3.

Legchenko, A., Baltassat, J-M., Bobachev, A., Martin, C., Robin, H., and Vouillamoz, J-M., 2004. Magnetic resonance sounding applied to aquifer characterization: Journal of Ground Water, 42(3), 363-373, doi: 10.1111/j.17456584.2004.tb02684.x.

Legchenko, A., Descloitres, M., Bost, A., Ruiz, L., Reddy, M., Girard, J-F., Sekhar, M., Kumar, M. S., and Braun, J-J, 2006. Resolution of MR Soundings applied to the characterization of hard rock aquifers, Journal of Ground Water, 44(4), 547-554, doi: 10.1111/j.1745-6584.2006.00198.x.

Legchenko, A., 2013. Magnetic resonance imaging for groundwater, Wiley-ISTE, ISBN: 978-1-84821-568-9.

Legchenko, A., and Pierrat, G., 2014. Glimpse into the design of MRS instrument, Near Surface Geophysics, 12(2), 297 - 308, doi: 10.3997/1873-0604.2014006.

Legchenko, A., Vouillamoz, J.M., Lawson, F.M.A., Alle, C., Descloitres,M., and Boucher, M., 2016. Interpretation of magnetic resonance measurements in the 
varying Earth's magnetic field, Geophysics, 81(4), WB23-WB31, doi: 10.1190/GEO2015-0474.1.

Marsaglia, G., and Zaman, A., 1991. A new class of random number generators, Annals of Applied Probability 1, 462-480, doi: 10.1214/aoap/1177005878.

Misstear, B.D.R., Brown, L., Hunter Williams, N., 2008. Groundwater recharge to a fractured limestone aquifer overlain by glacial till in County Monaghan, Ireland, Quarterly Journal of Engineering Geology and Hydrogeology, 41(4), 465-476, doi: 10.1144/1470-9236/07-084.

Mohnke, O, and Yaramanci, U., 2002. Smooth and block inversion of surface NMR amplitudes and decay times using simulated annealing, Journal of Applied Geophysics, 50, 163-177, doi: 10.1016/S0926-9851(02) 00137-4.

Müller-Petke, M., and Yaramanci, U., 2008. Resolution studies for Magnetic Resonance Sounding (MRS) using the singular value decomposition, Journal of Applied Geophysics, 66, 165-175, doi: 10.1016/j.jappgeo.2007.11.004.

Parsekian, A.D., Grombacher, D., 2015. Uncertainty estimates for surface nuclear magnetic resonance water content and relaxation time profiles from bootstrap statistics, Journal of Applied Geophysics, 119, 61-70, doi: 10.1016/j.jappgeo.2015.05.005.

Sambridge, M., and Mosegaard, K., 2002. Monte-Carlo methods in geophysical inverse problems, Reviews of Geophysics, 40, 1009, doi: 10.1029/2000RG000089.

Schirov, M., Legchenko, A., and Creer, G., 1991. New direct non-invasive ground water detection technology for Australia, Exploration Geophysics, 22, 333-338, doi: 10.1071/EG991333. 
Semenov, A.G., 1987. NMR Hydroscope for Water Prospecting, Seminar on Geotomography, Indian Geophysical Union, Hyderabad, Proceedings, 66-67.

Tikhonov, A., and Arsenin, V., 1977. Solution of ill-posed problems, John Wiley \& Sons, Inc.

Trushkin, D.V., Shushakov, O.A., and Legchenko, A.V., 1994. The potential of a noise-reducing antenna for surface NMR ground water surveys in the earth's magnetic field, Geophysical Prospecting, 42, 855-862, doi: 10.1111/j.13652478.1994.tb00245.x.

Vouillamoz, J.M., Hoareau, J., Grammare, M., Caron, D., Nandagiri, L., and Legchenko, A., 2012. Quantifying aquifer properties and freshwater resource in coastal barriers: a hydrogeophysical approach applied at Sasihithlu (Karnataka state, India), Hydrology and Earth System Sciences, 16(11), 4387 4400, doi: 10.5194/hess16-4387-2012.

Weichman, P.B, Lun, D.R, Ritzwoller, M.H, and Lavely, E., 2002. Study of surface nuclear magnetic resonance inverse problems, Journal of Applied Geophysics, 50, 129-147, doi: 10.1016/S0926-9851(02)00135-0.

Weng, A., 2010. Occam's inversion of magnetic resonance sounding on a layered electrically conductive earth, Journal of Applied Geophysics, 70, 84-92, doi: 10.1016/j.jappgeo.2009.12.006. 


\section{Figure caption}

Figure 1. Discretization of the linear equation: a) the amplitude of the MRS signal generated by a 1-m-thick layer of bulk water versus depth of this layer; b) the thickness of the model layers versus depth; c) the diagonal elements of the model resolution matrix.

Figure 2. Inversion of a 1-layer model: a) the solution given by regularization with the error bars corresponding to the standard deviation estimated with the SVD; b) the $\mathrm{V}_{\max }$ and $\mathrm{V}_{\min }$ solutions; $\mathrm{c}$ ) the diagonal elements of the model resolution matrix.

Figure 3. Inversion of a 1-layer model: the data set (circles) and the theoretical signals computed after inversion results $(\mathrm{RMSE}=2.9 \mathrm{nV})$.

Figure 4. Inversion of a 1-layer model: a) the PDF computed counting RMSE distribution (solid line) and the PDF computed with the assumption of a normal distribution of RMSE (dashed line); b) the PDF of V; c) the mean volume of water versus RMSE (solid line) with corresponding standard deviation (dashed lines). All the equivalent solutions are ranged along the grey line $(\mathrm{RMSE}=2.9 \mathrm{nV})$ with crosses showing solutions corresponding to $\mathrm{V}_{\max }, \mathrm{V}_{\text {regulariz }}$ and $\mathrm{V}_{\min }$.

Figure 5. Inversion of a 2-layer model: a) the solution given by regularization; b) the $\mathrm{V}_{\max }$ and $\mathrm{V}_{\min }$ solutions; $\mathrm{c}$ ) the diagonal elements of the model resolution matrix.

Figure 6. Location of the investigated area in the Northern Ireland is shown by a black star: a) general map; b) geological formations in County of Donegal.

Figure 7. Inversion of experimental data set obtained near borehole GO-3: a) the borehole $\log$; b) the resistivity $\log$; c) the solution given by regularization; d) the $V_{\max }$ and $\mathrm{V}_{\min }$ solutions; e) the diagonal elements of the model resolution matrix. 
Figure 8. Inversion of experimental data set obtained near borehole GO-3: a) the PDF computed counting RMSE distribution (solid line) and the PDF computed with the assumption of a normal distribution of RMSE (dashed line); b) the PDF of V; c) the mean volume of water versus RMSE (solid line) with corresponding standard deviation (dashed lines). The grey line shows RMSE values for all the equivalent solutions and the crosses show the volumes of water for the solutions corresponding to $\mathrm{V}_{\max }, \mathrm{V}_{\text {regulariz }}$ and $\mathrm{V}_{\min }$.

Figure 9. Inversion of experimental data set obtained near borehole GO-1: a) the borehole $\log$; b) the resistivity $\log$; c) the solution given by regularization; d) the $V_{\max }$ and $\mathrm{V}_{\min }$ solutions; e) the diagonal elements of the model resolution matrix.

Figure 10. Measured amplitude of the MRS signal versus pulse moment (circles) and the theoretical signals computed after inversion results: a) borehole GO-1; b) borehole G03. 


\section{Tables}

\begin{tabular}{|c|c|c|c|c|c|}
\hline Data set & $\begin{array}{c}\mathrm{V}_{\min } \\
\left(\mathrm{m}^{3} / \mathrm{m}^{2}\right)\end{array}$ & $\begin{array}{c}\mathrm{V}_{\text {regulariz }} \\
\left(\mathrm{m}^{3} / \mathrm{m}^{2}\right)\end{array}$ & $\begin{array}{c}\mathrm{V}_{\max } \\
\left(\mathrm{m}^{3} / \mathrm{m}^{2}\right)\end{array}$ & $\begin{array}{c}\text { RMSE } \\
(\mathrm{nV})\end{array}$ & Commentaries \\
\hline 1-layer model & 0.56 & 0.6 & 0.73 & 2.9 & $\mathrm{~V}_{\bmod }=0.5\left(\mathrm{~m}^{3} / \mathrm{m}^{2}\right)$ \\
\hline 2-layer model & 1.1 & 1.3 & 1.5 & 2.85 & $\mathrm{~V}_{\text {mod }}=1.0\left(\mathrm{~m}^{3} / \mathrm{m}^{2}\right)$ \\
\hline $\begin{array}{l}\text { Field data near } \\
\text { borehole GO-3 }\end{array}$ & 1.35 & 1.46 & 1.55 & 5.1 & $\begin{array}{c}\text { Shallow soil layer } \\
\text { over bedrock }\end{array}$ \\
\hline $\begin{array}{c}\text { Field data near } \\
\text { borehole GO-1 }\end{array}$ & 0.23 & 0.25 & 0.37 & 0.48 & Bedrock \\
\hline
\end{tabular}

Table 1. Summary of the inversion results corresponding to the examples presented in this paper. 
a)

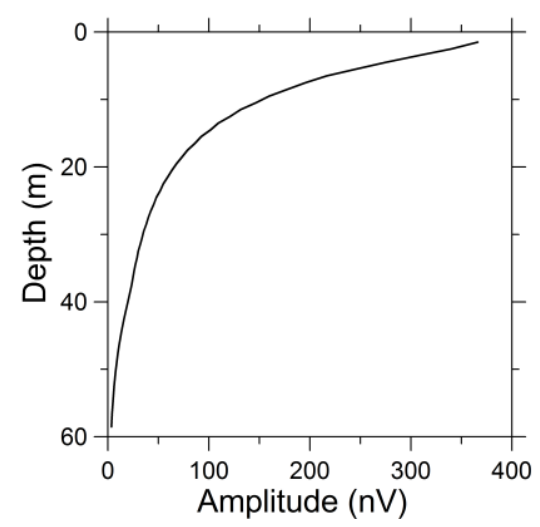

b)

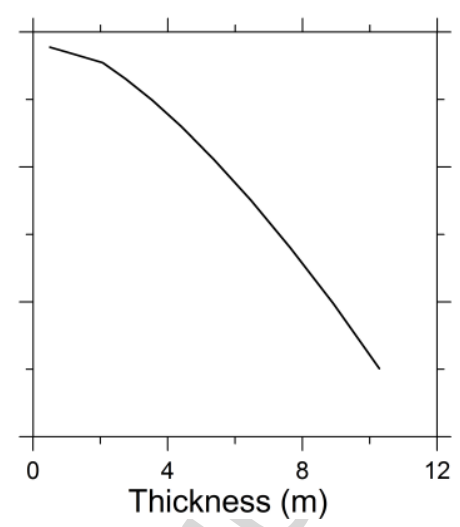

c)

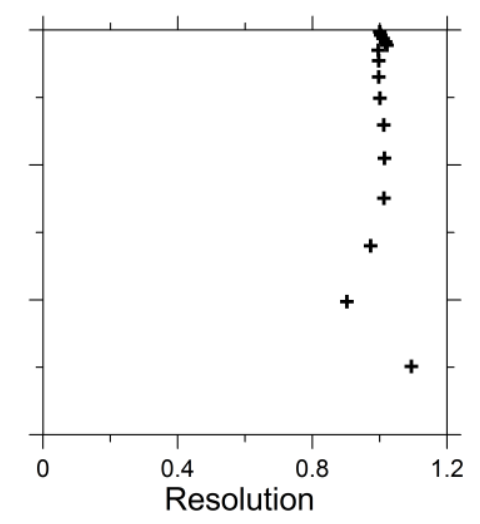

Figure 1 
a)

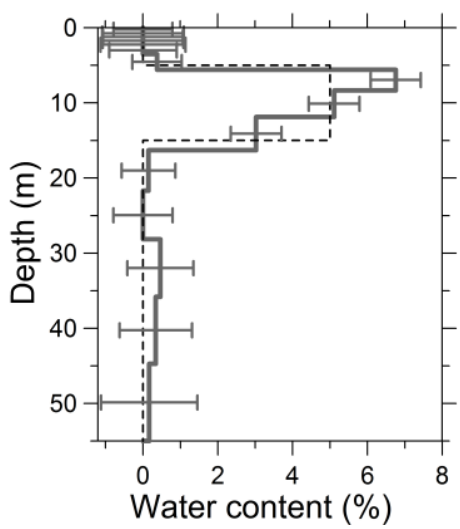

b)

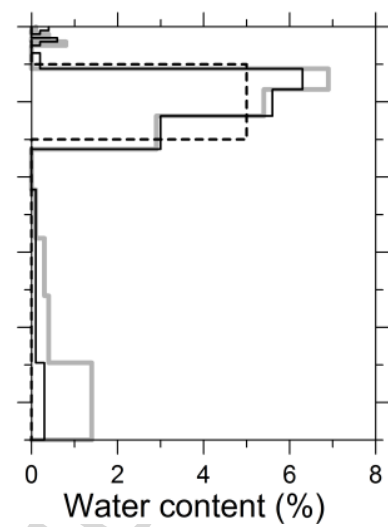

c)

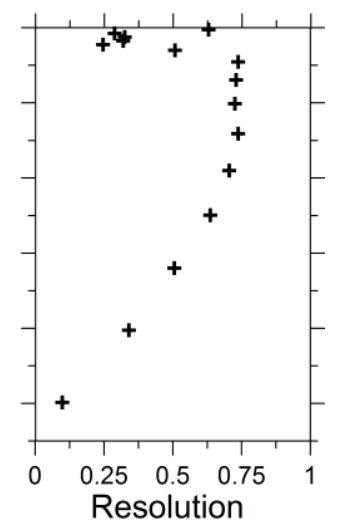

Figure 2 


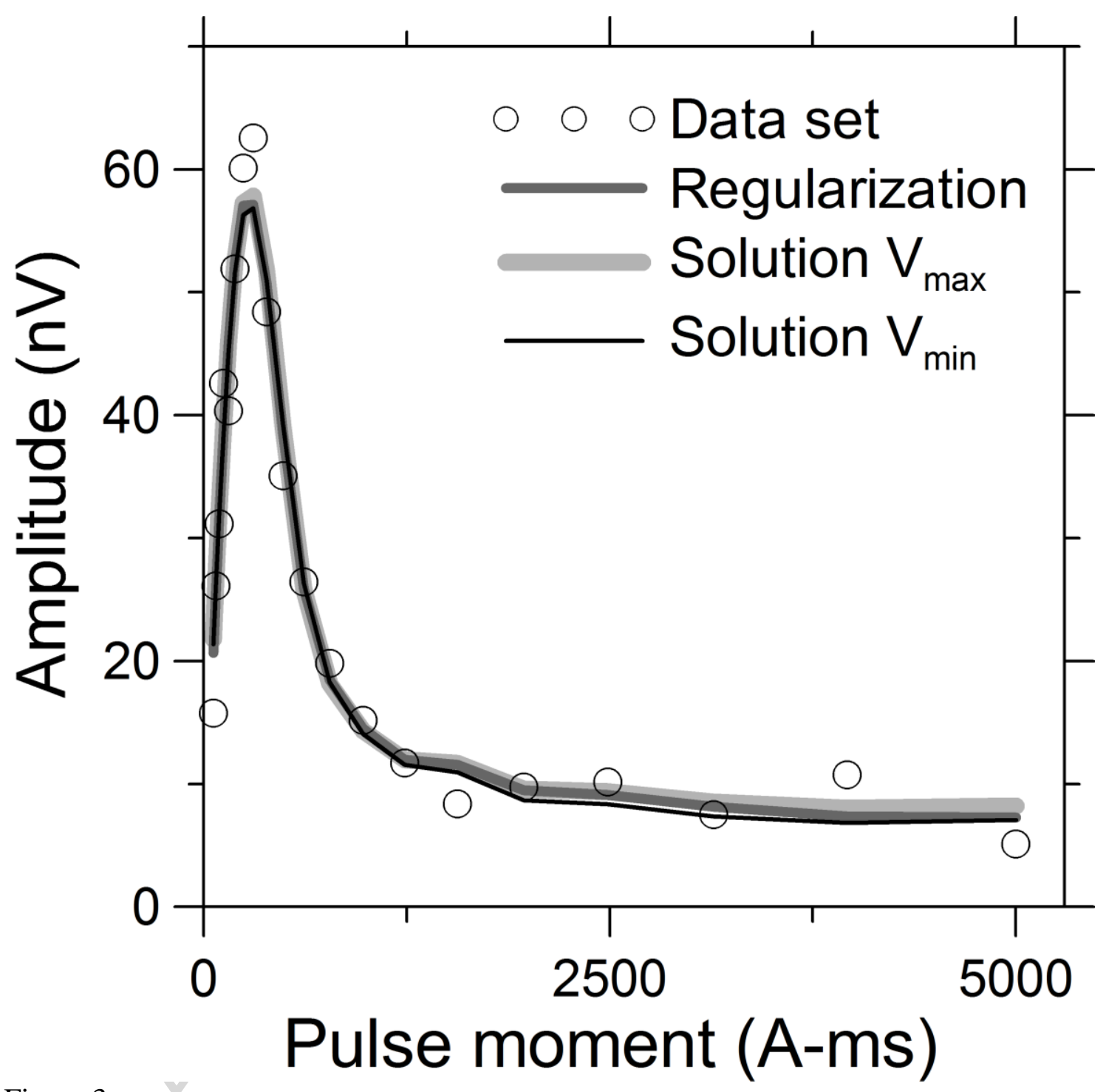

Figure 3 
a)

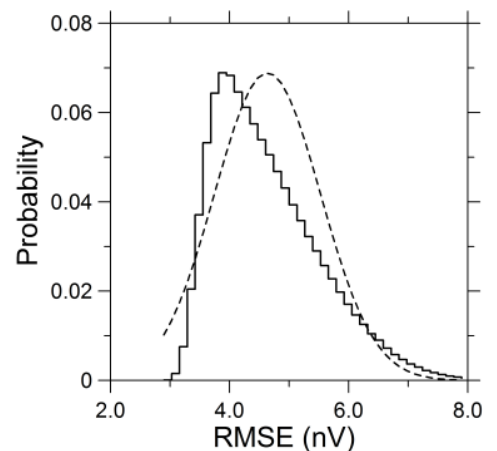

Figure 4 b)

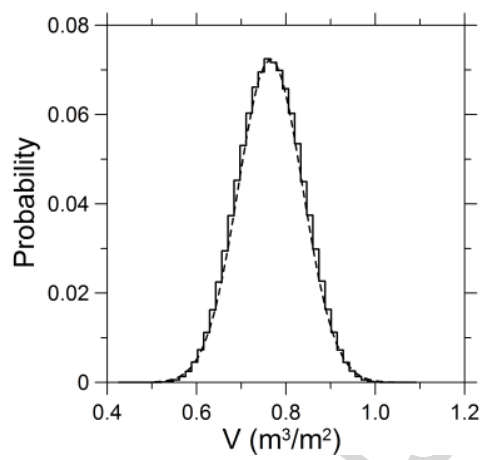

c)

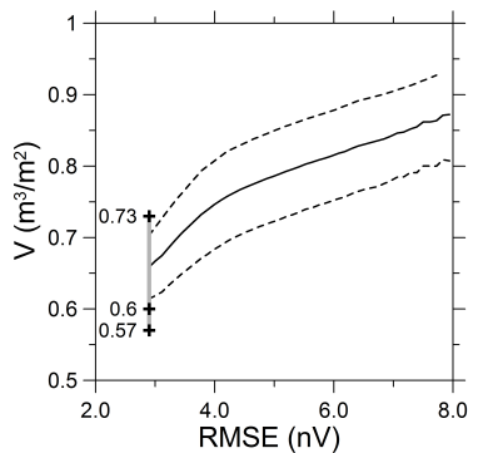


a)

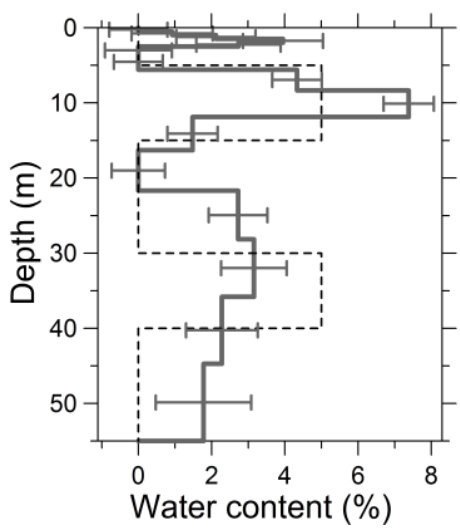

b)

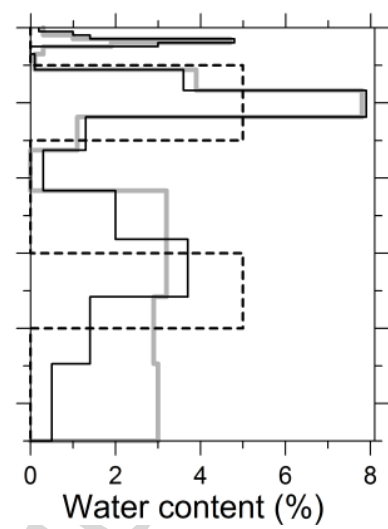

c)

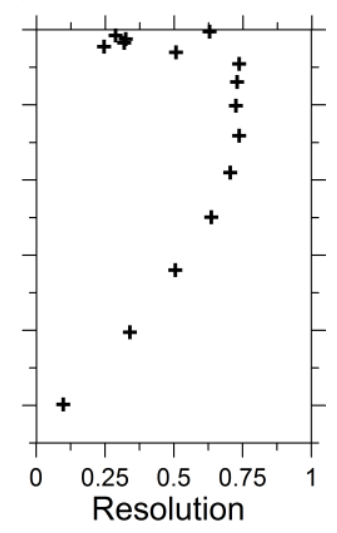

Figure 5 

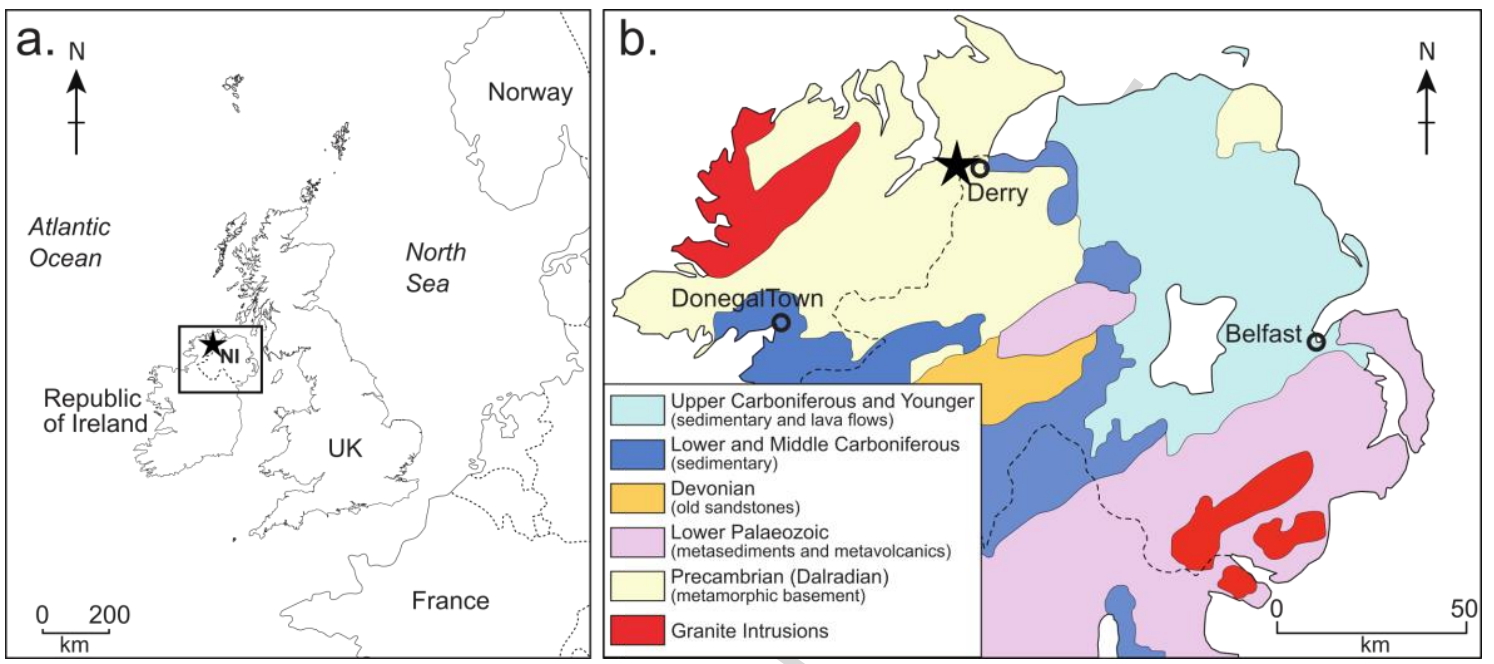

Figure 6 
a)

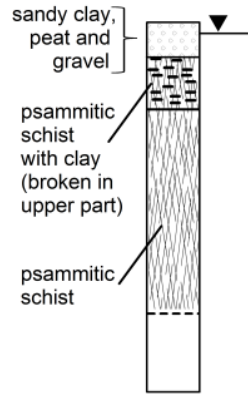

Figure 7 b)

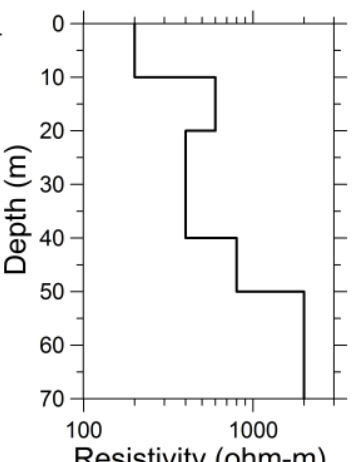

c)

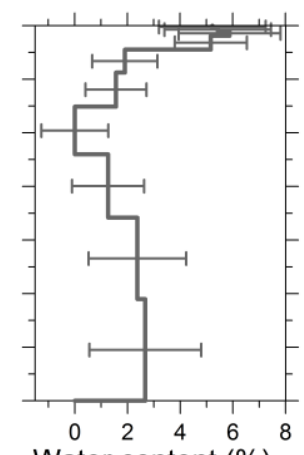

Water content (\%) d)

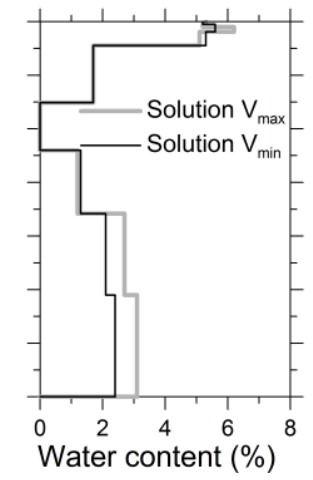

e)

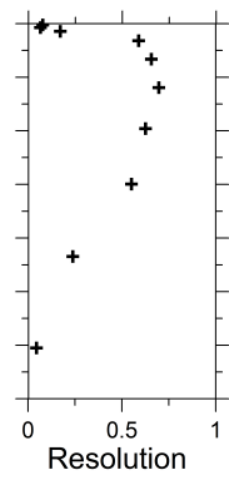


a)

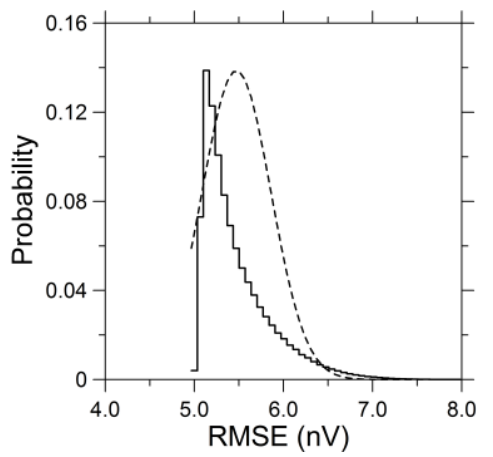

Figure 8 b)

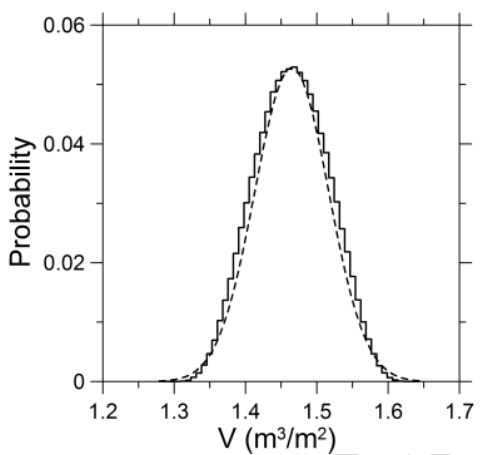

c)

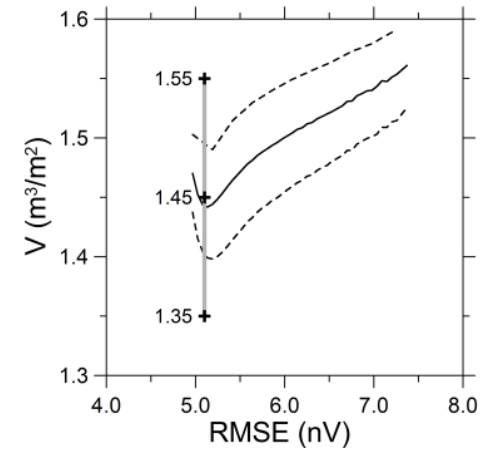


a)

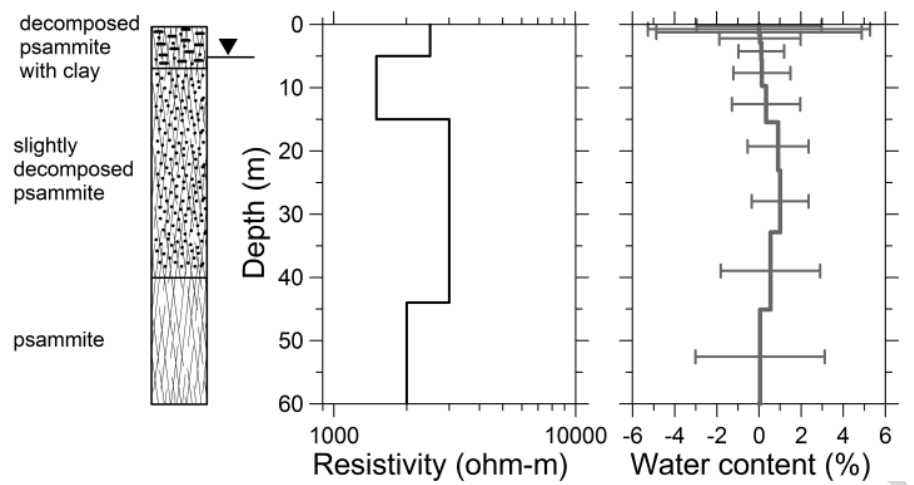

Figure 9 b)

c)

d)

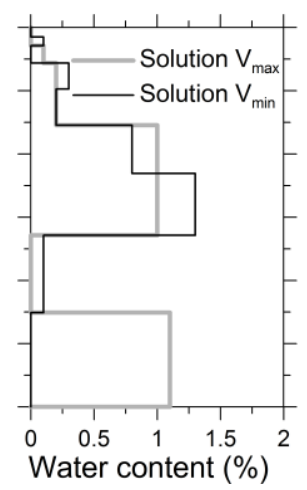

e)

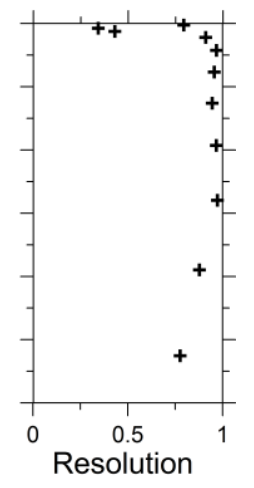


a)
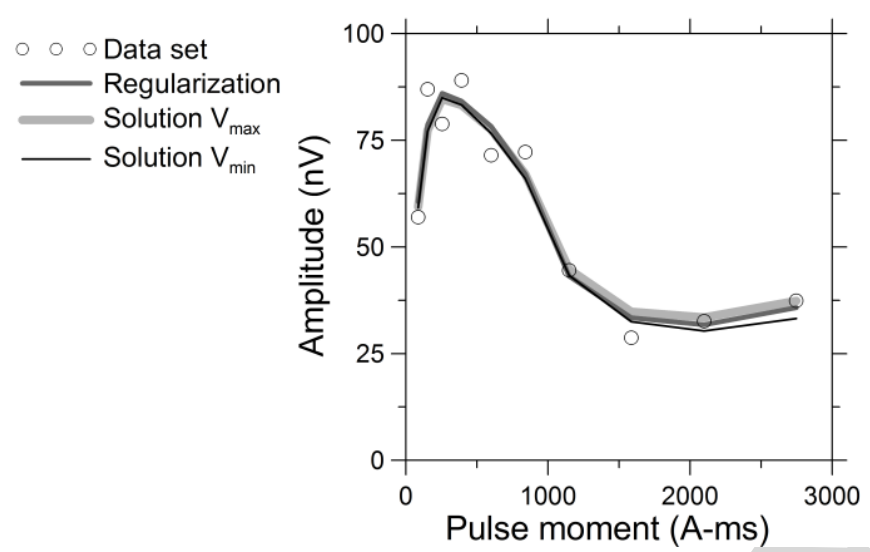

Figure 10 b)

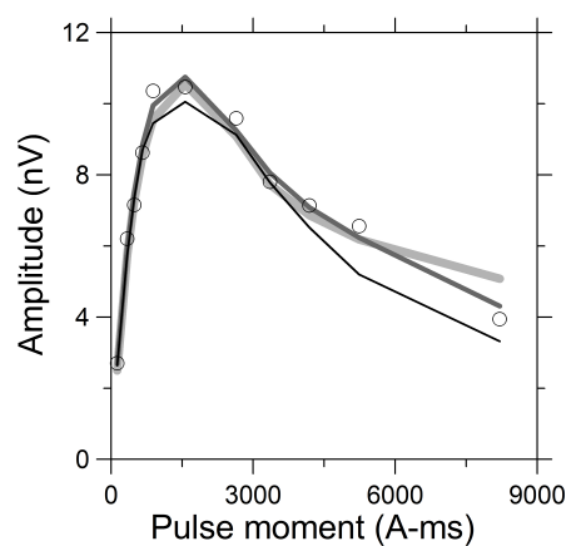




\section{Highlights}

- An efficient method of investigating uncertainty in SNMR inversion is proposed.

- SNMR is able to provide an estimate of the water volume.

- A Monte Carlo simulation allows analyzing linear or nonlinear inverse problems.

- The method is efficient for investigating Irish bedrock aquifers. 